Fixed Point Theory, 20(2019), No. 1, 19-30

DOI: $10.24193 /$ fpt-ro.2019.1.02

http://www.math.ubbcluj.ro/ nodeacj/sfptcj.html

\title{
ON GREGUS-ĆIRIĆ MAPPINGS ON WEIGHTED GRAPHS
}

\author{
MONTHER RASHED ALFURAIDAN* AND MOHAMED AMINE KHAMSI** \\ * Department of Mathematics \& Statistics \\ King Fahd University of Petroleum and Minerals \\ Dhahran 31261, Saudi Arabia \\ E-mail: monther@kfupm.edu.sa \\ ** Department of Mathematical Sciences \\ University of Texas at El Paso \\ El Paso, TX 79968, USA \\ E-mail: mohamed@utep.edu
}

\begin{abstract}
In this paper, we introduce the concept of monotone Gregus-Ćirić-contraction mappings in weighted digraphs. Then we establish a fixed point theorem for monotone Gregus-Ćirić-contraction mappings defined in convex weighted digraphs.

Key Words and Phrases: Fixed point, Gregus-Ćirić-contraction, monotone mappings, weighted graph.

2010 Mathematics Subject Classification: 47H09, 47H10.

Acknowledgements. The authors would like to acknowledge the support provided by the Deanship of Scientific Research at King Fahd University of Petroleum \& Minerals for funding this work through project No. IN141040.
\end{abstract}

\section{REFERENCES}

[1] M.R. Alfuraidan, On monotone Ćirić quasi-contraction mappings with a graph, Fixed Point Theory Appl., 2015(2015), 93.

[2] M. Bachar, M.A. Khamsi, On monotone Ćirić quasi-contraction mappings, J. Math. Ineq., 10(2016), no. 2, 511-19.

[3] S. Banach, Sur les opérations dans les ensembles abstraits et leurs applications, Fund. Math., 3(1922), 133-181.

[4] L.M. Blumenthal, Theory and Applications of Distance Geometry, Oxford Univ. Press, London, 1953.

[5] Lj. B. Ćirić, A generalization of Banach's contraction principle, Proc. Amer. Math. Soc., 45(1974), 267-273.

[6] Lj. B. Ćirić, On a generalization of Gregus fixed point theorem, Czechoslovak. Math. J., 50(2000), 449-458.

[7] B. Djafari-Rouhani, S. Moradi, On the existence and approximation of fixed points for Ćirić type contractive mappings, Quaestiones Math., 37(2014), no. 2, 179-189.

[8] M. Gregus Jr., A fixed point theorem in Banach space, Boll. Un. Mat. Ital. Sez. A Mat.Soc. Cult., 80(517)(1980), 193-198.

[9] J. Jachymski, The contraction principle for mappings on a metric space with a graph, Proc. Amer. Math. Soc., 136(2008), 1359-1373. 
[10] K. Menger, Untersuchungen über allgemeine Metrik, Math. Ann., 100(1928), 75-163.

[11] A.C.M. Ran, M.C.B. Reurings, A fixed point theorem in partially ordered sets and some applications to matrix equations, Proc. Amer. Math. Soc., 132(2004), no. 5, 1435-1443.

[12] S. Reich, I. Shafrir, Nonexpansive iterations in hyperbolic spaces, Nonlinear Anal., 15(1990), 537-558.

[13] W. Takahashi, A convexity in metric spaces and nonexpansive mappings, Kodai Math. Sem. Rep., 22(1970), 142-149.

Received: September 6, 2016; Accepted: April 10, $201 \%$. 
